\title{
Innovation and Digital Marketing Adoption in Mexican Small Business
}

\author{
Adriana M. Noyola-Medina ${ }^{1}$, Sandra Y. Pinzón-Castro ${ }^{1} \&$ Gonzalo Maldonado-Guzmán $^{1}$ \\ ${ }^{1}$ Centro de Ciencias Económicas y Administrativas, Universidad Autonoma de Aguascalientes, Mexico \\ Correspondence: Adriana M. Noyola-Medina, Centro de Ciencias Económicas y Administrativas, Universidad \\ Autonoma de Aguascalientes, Aguascalientes, Mexico.
}

$\begin{array}{ll}\text { Received: March 15, } 2018 & \text { Accepted: April 13, } 2018 \quad \text { Online Published: May 14, } 2018 \\ \text { doi:10.5539/jms.v8n2p18 } & \text { URL: https://doi.org/10.5539/jms.v8n2p18 }\end{array}$

\begin{abstract}
Today, companies are under enormous pressure to innovate (Steinhoff \& Trommosdorff, 2013) due to rapid technological evolution, reduced product life cycles and globalized markets (Rovira \& Tolstoy, 2016), coupled with the fact that the user is increasingly interactive with digital media, which emphasizes the fact that companies must have presence on the web to be able to cope with the current environment. The main objective of the present study is to investigate how innovation in products, processes, marketing and organization generates opportunities for efficient marketing of companies, transforming it into digital marketing. The present study was carried out in a sample of 256 companies in the state of Aguascalientes (Mexico) using the technique of structural equations modeling (SEM), where the results show positive and significant effects of the innovation on the adoption of digital marketing.
\end{abstract}

Keywords: digital marketing adoption, innovation, small business

\section{Introduction}

Discussing innovation has become one of the most important current topics as it is considered one of the factors that have more impact in the organizations that can help them to compete efficiently and provide them global success (Christensen, 1997; Schumpeter, 1934; seen in Kusiak, 2007, p. 863). Along with its fast evolution and adaptation to the new needs of the environment, it can be said that innovation, i.e. technological innovation, has produced a universally accepted and used tool which is Internet. Considering that this tool has turned into an important format for every business, researchers suggest that Internet will substitute the person-to-person business or the physical location of different shops (Evans, 1996; Van Tassel \& Weitz, 1997).

For that reason, and taking into consideration the aspects of innovation and changes in the context, marketing must take advantage of the tools that innovation offers by facing a new system: e-business (Chaffey \& Ellis-Cahdwick, 2014). Due to the importance of this implementation in marketing and the several benefits it provides, a lot of interest has been raised among researchers and business entities (Mulhern, 1997; Hart, Doherty, $\&$ Ellis-Chadwick, 2000). Along with this, there is the question regarding the actual role of innovation in the adoption of digital marketing in enterprises.

Regarding the term of innovation, it can be said that the concept has been widely studied. However, there is not a consensus about the contributions made by every researcher as each one of them has a personal and unique perspective besides using a wide range of variables linked to different descriptions of processes (Kusiak, 2007). This shows that there is still a long way in the study and integration of innovation not only in a conceptual way, but also to determine a reliable and useful system of indicators (Echeverría, 2008). Among the innovation concepts that are more closely linked to the topic of this investigation, there is one from Galanakis (2006, p. 1223) which states that innovation "is the creation of new products, processes, knowledge or services through the use of scientific or technological knowledge, either new or existing, which provides a degree of novelty to the developer, the industrial sector, nation or the world to be successful in the market." The concept from Drucker (1985; seen in Pinzón, 2009, p. 92), refers to innovation as "(...) a means to take advantage of change as an opportunity for a different business (...) Innovation creates a resource, it does not exist until someone finds the use of something natural and provides it with an economic value."

A quick observation to these definitions show that they focus in the idea that innovating does not only refer to 
create new products but it is also possible to do so through new processes or methods started by an executives. This could be related to the implementation of the marketing strategy through digital means creating in this way digital marketing inside the organizations. Similarly, it is possible to understand that, through innovation, executives can make use of the changes produced by the Internet. In other words, it is evident the increasing use of internet tools such as email, web sites, social networks, and so on by consumers so it can be assumed that executives take advantage of all these tools and produce a benefit for their enterprise.

Likewise, as it was mentioned earlier, there is a wide range of scales and methods to measure innovation due to the lack of agreement in the term and the study of the variable which, according to Pinzón (2009), can be measured through four main constructs: products innovation, process innovation, marketing innovation and organization innovation. This may be the best-contextualized measurement option for the environment of Aguascalientes since it has been used in different researches related to the state with acceptable results in reliability and validity. It is important to mention that each term was defined by using the manual of Oslo (OCDE, 2005), which is one on the main references in the study of innovation.

Regarding the definition of digital marketing, Wu, Mahajan, \& Balasubramanian (2003) identify it as "the use of Internet technologies to link customers, suppliers, business partners, and employees using at least one of the following: (a) e-commerce Web sites that offer sales transactions, (b) intranets and enterprise data, (c) extranets and supply chains, and (d) IP electronic data interchange". In a similar trend, the concept of Chaffey \& Ellis-Chadwick (2014) about digital marketing is as simple as to describe it as "achieving marketing objectives through the implementation of digital technologies". Both concepts establish that enterprises must adopt the existing technologies in order to be part of the virtual world. According to Chaffey \& Ellis-Chadwick (2014), it is and additional way in which the marketing specialist can implement some marketing goals as well as help the executive to build and manage relations with clients, suppliers, employees and associates and ultimately provide potential to all the enterprises that adopt e-business.

There is a great demand produced by the consumer regarding the use of Internet, not only as a communication tool but it has also become important when taking a decision because of the diversity of activities that can be done with it. Some of these activities include obtaining more information about a product or a specific topic, erasing the geographical barriers as it easy to get or compare a product anywhere in the world as well as having a faster and more direct communication with the enterprise or supplier (Westland \& Au, 1998). Nonetheless, despite the seeming advantages of adopting digital marketing in enterprises, there is little specialized literature that focuses on this topic; it is fundamental to produce empirical investigations that strengthen this new area of research (Brodie, Winklhofer, Covielo, \& Johnston, 2007; Ciarniene \& Stankeviciute, 2015).

For this reason, the present investigation shows the results of the analysis obtained about innovation and the adoption of digital marketing in enterprises in Aguascalientes State (Mexico), where 256 enterprises were used as the sample. It is important to notice that one of the main contributions of this research is that it focuses in the study of the variables of innovation and digital marketing focused in the enterprises as there is no evidence of empirical works in the literature where both variables are related. Accordingly, it is important to mention that the theoretical model proposed in this research was analyzed with the methodology of Structural Equation Modeling (SEM), which gives way to the discussion of the results considering the theoretical model as a whole.

Similarly, the main goal of this research is to analyze the adoption of digital marketing through the innovation of enterprises in Aguascalientes States by using a sample of 256 enterprises that belong to the industrial, commercial and services sectors that used some digital marketing tools (Internet, smartphones, web sites, social networks, email, and so on) in their organization. It is necessary to highlight that rest of the paper has been organized in the following way: the literature regarding the topic (theory and empirical studies) in order to validate the study of the relation of both variables (innovation and the adoption of digital marketing) and establish the hypothesis of the research. The third section explains the methodology of the research, the sample and the variables used; the fourth section analyzes the results obtained in order to compare it with the established hypothesis of the investigation and, in the final section, the main conclusions and the main discussions of the empirical research are presented.

\section{Literature Review}

Many investigations have proved that the enterprises that do not take complete advantage of technologies and the solutions they offer currently such as electronic trade (which is one of the many uses of digital marketing and that most consumers look for as a new and main characteristic in enterprises), will be hardly labelled as enterprises that have taken advantage of them because many executives do not have the human capital or the knowledge to implement it in their web site. Such companies lose many clients; that is why the enterprises that 
do not implement it become more vulnerable to the economic changes (Arendt, 2007). Selwyn \& Gorard (2002; seen in Arendt, 2007) as well as Braun (2002) point out that there is a threat for those enterprises that do not use innovations and digital marketing. This can be the potential elimination of the existing relations with society including "online" consumers and those that are still "offline" which creates a multi-dimensional, socioeconomic phenomenon where the networks and knowledge are essential assets to guarantee the success of an enterprise in this new economy.

All enterprises in the different industries have adopted initiatives of digital marketing in order to improve the management of their internal business processes as well as evolve their relations with the environment. In this regard, it is important to highlight and infer the fact that enterprises will need to have innovation as a first step so they can later implement the digital marketing for their company. In this regard, Cooke (1996; seen in Braun, 2002 , p. 14) emphasizes in his investigations that in order for a region or state to grow is that it should come from the innovation based on a network which refers to obtain knowledge from others and once such knowledge is produced and implemented in the enterprise then it must be shared with others. From this, it is possible to understand and link it to the topic discussed because if a manager has the adequate technological resources, understands and carries out correctly the implementation of digital marketing in the company then the manager can become an example as a model for other executives that are interested in innovating in that way.

Moreover, it is possible nowadays to take the previous statement and indicate that, even if it is true that the relations between consumers and enterprises are the main motivation for a market oriented company, along with the new trend of digital marketing, it provides more support to the decisions made by executives as a result of the relation they have with the target market through these new instruments. These relations could be labelled as innovating since they use new technologies provided by the innovation in technologies of information and communication (TICs) and offer knowledge and its transfer, create more dynamic relations and enhance the assets of companies (Amin, 1999; Cooke, 1996; seen in Braun, 2002).

Accordingly, the literature emphasizes that innovations benefit not only the ones that adopt them by providing competitive advantages, functional differentiation, administrative intensity as well as internal and external communication (Baldrige \& Burnham, 1975; Kimberly \& Evanisko, 1981; Hull \& Hage, 1982; Damanpour, 1987; Abrahamson \& Rosenkopf, 1993; Mahajan \& Balasubramanian, 2003), but they are also updated regarding their competitors, an imperative need for any executive. Furthermore, it is mentioned that the trend of being part of the virtual world that, according to $\mathrm{Wu}$, Mahajan, \& Balasubramanian (2003), was a guideline promoted by enterprises that want to innovate constantly. Also, enterprises that have a competitive advantage based in innovation will be closer to achieve success (Kotler \& Armstrong, 2008; Steinhoff \& Trommsdorff, 2013).

Regarding this issue, Drucker (1954) pointed out that the two main functions of a company are marketing and innovation because the result of a complicated environment regarding technology produces a higher demand of more sophisticated marketing which can face the underdeveloped competition in commercialization and in the comprehension of the clients' needs (seen in Mohr \& Sarin, 2009). It is possible to infer that it is not important the moment where the enterprise is, it will always be valid that executives think about improving their current activities and use the advantages provided by the new technologies and this implies the evolution of their marketing strategy, one that is more appropriate to the innovation context which is taking place in the organization.

This creates the following question: why do not executives evolve or try to complement their traditional marketing strategy with new technologies despite the fact they have them? Arendt (2007) states that there are two big barriers that stop businesspeople from digital marketing: the macroeconomic and microeconomic barriers. The first barrier refers to the lack of culture regarding innovation, that is, it shows that executives do not have the initiative of integrating the new aspects they see around them into their enterprise. This comes before the lack of flexibility of the production environment, i.e., the interoperability, which has to do with the categorization of the problems focused on technical, legal, semantic and organizational aspects along with the investment in networks and services. To sum up, enterprises lack the new generation of network infrastructure, access methods and network services that guarantee a strong competitive position.

Regarding the microeconomic barrier, the author mentions as main problem the lack of awareness and skills in enterprises to have a low level of innovation in the use of TICs as well as the lack of the necessary knowledge to select the most adequate technology for their enterprise in a context that is changing constantly. Furthermore, they do not have workers with enough knowledge to implement new innovations and techniques such as digital marketing. In the same way that the lack of knowledge from the consumer that the company uses the innovation in technology and digital media, the lack of adoption to the technological changes and the lack of adoption of the 
flow of solutions with digital content to the requirements of the digital economy. Thus, it must be emphasized that managers of enterprises invest in training every employee so they have the basic skills and knowledge that help to a fast and easy implementation of the benefits of digital techniques (Arendt, 2007).

On the other hand, Steinhoff \& Trommosdorff (2013) mentioned that it is still difficult the aspect of innovating in the process of knowing the client deeply, which is why the traditional methods have their limitation and require the use of new innovating and intelligent methods that can overcome such complications. This brings up the fact about the big amount of information that web sites can provide to researchers and managers and their easy access, which is one of the main channels in which consumers or users share common information; this highlights the advantages of implementing digital marketing in enterprises. Likewise, Trivedi (2013) reiterates the fact that the organizations evolve in the knowledge process of consumers through innovating practices, mostly in marketing, emphasizing the use of Internet (digital marketing), which will produce more adequate strategies to the current market.

Trainor, Rapp, Beitelspacher, \& Schillewaert (2011) establish that the incorporation of innovation through new technologies is a key component in order to create digital marketing inside enterprises that would provide a better interaction with clients and give a better and higher access to information (El-Gohoray, 2010), at the same time that the enterprise would show an image of quality (Hamidi \& Safabakhsh, 2011), by taking advantage of the new technologies.

\section{Method}

To sum up, based on the literature analyzed and the context that exists currently around enterprises and the consumer, in the specific case of the use of innovation and the implications in adopting digital marketing in enterprises in Aguascalientes (Mexico), the following research hypothesis is stated for this investigation:

\section{$H_{1}$ : Innovation has an impact in the adoption of digital marketing in small business.}

It is important to mention that this empirical research in enterprises from Aguascalientes State used the business directory of the Sistema de Información Empresarial Mexicano (System of Mexican Business Information, or SIEM) with the latest version of 2010 as reference. It contains 4,929 economic units that belong to the industry, business and services sectors including micro, small, medium and big enterprises. The sample was selected through a random marketing group, which produced a total of 256 enterprises with a sampling error of $\pm 5 \%$ and a level of reliability of $95 \%$. The data was collected through a questionnaire applied to managers or owners of enterprises.

The measuring instrument was created by using the measurement scales that already exist in the literature regarding innovation and the adoption of digital marketing. The scale used for innovation was proposed by Pinzón (2009), which considers four dimensions: product innovation; processes innovation; marketing innovation; and organization innovation with a total of 27 items. The scale used for digital marketing was developed by Dlodlo \& Dhurup (2013), which include five dimensions: perceived ease of use; external pressure and goal; job performance; availability of resources; and compatibility with a total of 13 items. Both measurements scales are based on a Likert-type scale of five positions from " $1=$ completely disagree to $5=$ completely agree" as limits.

An analysis of reliability and validity of the scales of innovation and the adoption of digital marketing was carried out with a Factorial Confirmatory Analysis (FCA) by using the method of maximum likelihood with the software EQS 6.1 (Bentler, 2005; Brown, 2006; Byrne, 2006). Furthermore, the reliability was evaluated with Cronbach's alpha, the Composite Reliability Index (CRI) (Bagozzi \& Yi, 1988) and the Variance Extracted Index (VEI) (Fornell \& Larcker, 1981; Hair, Anderson, Tatham \& Black, 1998; Luque, 2000). It is important to mention that the robust statistics were considered in order to provide a better statistical adjustment of the data (Satorra \& Bentler, 1988).

The adjustment indices used to prove the research hypothesis presented in the theoretical framework of innovation and the adoption of digital marketing were the Index of Normalized Adjustment (or, NFIT), the Index of Not Normalized Adjustment (or, NNFIT), the Index of Comparative Adjustment (or, CFI) and the Root Mean Square of Error Approximation (or RMSEA) (Bentler \& Bonnet, 1980; Byrne, 1989; Bentler, 1990; Chau, 1997; Hair, Anderson, Tatham, \& Black, 1998). These results are acceptable if the NFIT, NNFIT and CFI indices are between 0.80 and 0.89 . Consequently, it can be said that there is a reasonable adjustment of the theoretical model (Bentler, 2005; Brown, 2006; Byrne, 2006). Conversely, if the average of these three indices is equal or higher than 0.90 then it is an evidence of an excellent adjustment of the theoretical model (Jöreskog \& Sörbom, 1986). If the RMSEA values are lower than 0.080, then they are considered as acceptable (Jöreskog \& Sörbom, 1986; 
Hair, Anderson, Tatham, \& Black, 1998). On the other hand, a high internal consistency can be observed in the constructs as the nine analyzed factors have a Cronbach's alpha that is higher than 0.70 as suggested by Nunally \& Berntein (1994).

Tests were made to highlight the convergent validity and the discriminating validity of the scales analyzed for the development of the validity. In the tests of convergent validity the results obtained in the AFC were checked and they are presented in Table 1; they suggest that the theoretical model of final measurement model has a good adjustment $(\mathrm{S}-\mathrm{B} \chi 2=651.3054 ; \mathrm{df}=420 ; \mathrm{p}=0.00000 ; \mathrm{NFI}=0.866 ; \mathrm{NNFI}=0.937 ; \mathrm{CFI}=0.947$; RMSEA=0.049). Similarly the acceptable CRI value will have to be higher than 0.60 (Bagozzi \& Yi, 1998). For the specific case of this research, this value is higher to the established parameter, which proves the reliability of the scales and the model.

Finally, regarding the VEI, Fornell \& Larcker (1981), Hair, Anderson, Tatham \& Black (1998) as well as Luque (2000) suggest that it must be equal or higher than 0.50. Even when the dimension of marketing innovation has a lower value to the one expected, the rest of the dimensions satisfy the limit mentioned above. Küster, Vila, \& Aldás (2000) mention that this parameter is usually very conservative and it is possible to find in the literature several examples of accepted scales with lower VEIs. Considering this, it can be said that the results do not show validity problems.

Table 1. Internal consistency and convergent validity of the theoretical model

\begin{tabular}{|c|c|c|c|c|c|c|}
\hline Variable & Indicator & $\begin{array}{l}\text { Factor } \\
\text { Loading } \\
\end{array}$ & $\begin{array}{l}\text { Robust } \\
\text { t-Value }\end{array}$ & $\begin{array}{l}\text { Cronbach } \\
\text { Alpha }\end{array}$ & CRI & VEI \\
\hline \multirow{4}{*}{ Product Innovation } & IPD1 & $0.755^{* * *}$ & $1.000^{\mathrm{a}}$ & \multirow{4}{*}{0.849} & \multirow{4}{*}{0.852} & \multirow{4}{*}{0.593} \\
\hline & IPD2 & $0.841^{* * *}$ & 13.073 & & & \\
\hline & IPD3 & $0.644 * * *$ & 7.599 & & & \\
\hline & IPD4 & $0.824 * * *$ & 11.854 & & & \\
\hline \multirow{5}{*}{ Process Innovation } & IPC1 & $0.606^{* * *}$ & $1.000^{\mathrm{a}}$ & \multirow{5}{*}{0.877} & \multirow{5}{*}{0.881} & \multirow{5}{*}{0.600} \\
\hline & IPC2 & $0.776 * * *$ & 10.468 & & & \\
\hline & IPC3 & $0.798 * * *$ & 10.001 & & & \\
\hline & IPC4 & $0.826 * * *$ & 10.330 & & & \\
\hline & IPC5 & $0.843^{* * *}$ & 9.900 & & & \\
\hline \multirow{6}{*}{ Marketing Innovation } & IMK1 & $0.757 * * *$ & $1.000^{\mathrm{a}}$ & \multirow{6}{*}{0.860} & \multirow{6}{*}{0.826} & \multirow{6}{*}{0.443} \\
\hline & IMK2 & $0.700 * * *$ & 11.709 & & & \\
\hline & IMK3 & $0.612 * * *$ & 10.276 & & & \\
\hline & IMK5 & $0.610 * * *$ & 9.439 & & & \\
\hline & IMK6 & $0.601 * * *$ & 9.449 & & & \\
\hline & IMK7 & $0.698 * * *$ & 11.193 & & & \\
\hline \multirow{5}{*}{ Organizational Innovation } & IO1 & $0.808 * * *$ & $1.000^{\mathrm{a}}$ & \multirow{5}{*}{0.903} & \multirow{5}{*}{0.911} & \multirow{6}{*}{0.675} \\
\hline & $\mathrm{IO} 2$ & $0.907 * * *$ & 13.602 & & & \\
\hline & $\mathrm{IO} 3$ & $0.883 * * *$ & 12.033 & & & \\
\hline & IO4 & $0.750 * * *$ & 12.694 & & & \\
\hline & IO5 & $0.745 * * *$ & 11.113 & & & \\
\hline \multirow{3}{*}{ Perceived Ease of Use } & UP1 & $0.898 * * *$ & $1.000^{\mathrm{a}}$ & \multirow{3}{*}{0.844} & \multirow{3}{*}{0.907} & \\
\hline & UP2 & $0.846 * * *$ & 19.322 & & & \multirow[t]{2}{*}{0.765} \\
\hline & UP3 & $0.879 * * *$ & 23.018 & & & \\
\hline \multirow{2}{*}{ Expernal Presure and Goal } & PEM3 & $0.946^{* * *}$ & $1.000^{\mathrm{a}}$ & \multirow{2}{*}{0.727} & \multirow{2}{*}{0.929} & \multirow{2}{*}{0.867} \\
\hline & PEM4 & $0.919 * * *$ & 25.178 & & & \\
\hline \multirow{3}{*}{ Job Performance } & DL1 & $0.902 * * *$ & $1.000^{\mathrm{a}}$ & \multirow{3}{*}{0.920} & \multirow{3}{*}{0.921} & \multirow{3}{*}{0.795} \\
\hline & DL2 & $0.855 * * *$ & 14.977 & & & \\
\hline & DL3 & $0.917 * * *$ & 21.118 & & & \\
\hline \multirow{2}{*}{ Availability of Resources } & DR1 & $0.759 * * *$ & $1.000^{\mathrm{a}}$ & 0747 & 0754 & 0606 \\
\hline & DR2 & $0.797 * * *$ & 11.392 & 0.141 & 0.134 & 0.000 \\
\hline Compatibility & $\mathrm{CO} 1$ & $0.895^{* * *}$ & $1.000^{\mathrm{a}}$ & 0.886 & 0.888 & 0.798 \\
\hline Compatibility & $\mathrm{CO} 2$ & $0.892 * * *$ & 15.929 & 0.880 & 0.000 & 0.190 \\
\hline $\mathrm{S}-\mathrm{B} \chi^{2}(\mathrm{df}=420)=651.3054$ & $0.00000 ;$ & $66 ; \mathrm{NNFI}=$ & $37 ; \mathrm{CFI}=$ & 47; RMSEA & 0.049 & \\
\hline
\end{tabular}


Likewise, as part of the analysis of convergent validity, the values in the factorial loads were analyzed for the 27 items that belong to the nine factors of the innovation model and the adoption of digital marketing and it was found that they are significant $(\mathrm{P}<0.001)$ besides the fact that each value is over the established minimum parameter of 0.60 (Bagozzi \& Yi, 1998) as well as the average of the standardized factorial loads for every dimension of the model are higher than the value recommended of 0.70 (Hair et al., 1998).

Regarding the discriminant validity of the theoretical model, it is carried out through the reliability interval test and the extracted variance test, which can be observed in details in Table 2. The first test, with an interval of 95\% of reliability, it can be perceived that none of the individual latent elements of the matrix of correlation have the unit above the diagonal, that is, the value of 1 (Anderson \& Gerbing, 1988). Secondly, the extracted variance test is under the diagonal (Fornell \& Larcker, 1981), which establishes that the extracted variance index (square correlation) between each pair of constructs must be lower than their corresponding EVI. Therefore, it can be concluded that both measurements in this model provide enough evidence of reliability as well as convergent and discriminant validity.

Table 2. Discriminant validity of the theoretical model

\begin{tabular}{|c|c|c|c|c|c|c|c|c|c|}
\hline Variable & 1 & 2 & 3 & 4 & 5 & 6 & 7 & 8 & 9 \\
\hline 1 & & & & & & & & & \\
\hline $\begin{array}{l}\text { Product } \\
\text { Innovation }\end{array}$ & 0.593 & 0.283 & 0.507 & 0.199 & 0.004 & 0.013 & 0.132 & 0.000 & 0.001 \\
\hline $\begin{array}{l}2 \\
\text { Process } \\
\text { Innovation }\end{array}$ & $\begin{array}{l}0.344 \\
0.720\end{array}$ & 0.600 & 0.340 & 0.211 & 0.020 & 0.008 & 0.059 & 0.009 & 0.024 \\
\hline $\begin{array}{l}3 \\
\text { Marketing } \\
\text { Innovation }\end{array}$ & $\begin{array}{l}0.524- \\
0.900\end{array}$ & $0.419-0.747$ & 0.443 & 0.336 & 0.055 & 0.045 & 0.182 & 0.028 & 0.059 \\
\hline $\begin{array}{l}4 \\
\text { Organizational } \\
\text { Innovation }\end{array}$ & $\begin{array}{l}0.280- \\
0.612\end{array}$ & $0.289-0.629$ & $0.418-0.742$ & 0.675 & 0.016 & 0.055 & 0.064 & 0.018 & 0.044 \\
\hline $\begin{array}{l}5 \\
\text { Perceiven } \\
\text { Ease of Use } \\
6\end{array}$ & $\begin{array}{l}-0.071 \\
-0.201\end{array}$ & $0.042-0.242$ & $0.103-0.367$ & $0.011-0.243$ & 0.765 & 0.123 & 0.111 & 0.251 & 0.191 \\
\hline $\begin{array}{l}\text { External } \\
\text { Preassure } \\
\text { Goal }\end{array}$ & $\begin{array}{l}-0-037 \\
-0.263\end{array}$ & $-0.033-0.211$ & $0.065-0.357$ & $0.112-0.356$ & $0.217-0.485$ & 0.867 & 0.312 & 0.139 & 0.366 \\
\hline $\begin{array}{l}7 \\
\text { Job } \\
\text { Performance }\end{array}$ & $\begin{array}{l}0.179- \\
0.547\end{array}$ & $0.103-0.383$ & $0.253-0.601$ & $0.107-0.399$ & $0.179-0.487$ & $0.357-0.761$ & 0.795 & 0.120 & 0.352 \\
\hline $\begin{array}{l}8 \\
\text { Availability of } \\
\text { Resources }\end{array}$ & $\begin{array}{l}-0.126 \\
-0.142\end{array}$ & $\begin{array}{l}-0.004 \\
-0.196\end{array}$ & $0.039-0.295$ & $0.012-0.256$ & $0.371-0.631$ & $0.269-0.477$ & $0.213-0.481$ & 0.606 & 0.370 \\
\hline $\begin{array}{l}9 \\
\text { Compatibility }\end{array}$ & $\begin{array}{l}-0-130 \\
-0.198 \\
\end{array}$ & $0.029-0.281$ & 0.089-0.397 & $0.071-0.347$ & $0.287-0.587$ & 0.419-0.791 & $0.393-0.793$ & $0.456-0.760$ & 0.798 \\
\hline
\end{tabular}

\section{Results}

The analysis of the theoretical model of innovation and the adoption of digital marketing in the enterprises of Aguascalientes through the method of structural equations was carried out with the EQS 6.1 software (Bentler, 2005; Byrne, 2006; Brown, 2006). The statistical results obtained will help to compare the hypothesis stated in this research by considering the same variables to prove the structure of the complete theoretical model. Accordingly, the nomological validity of the theoretical framework of innovation and the adoption of digital marketing was examined through the Chi-square test, which compared the results obtained between the theoretical model and the measurement model. Such results indicate that the differences between both models are not significant which can offer an explanation of the relationships observed among the latent constructs (Anderson \& Gerbing, 1988; Hatcher, 1994). Table 3 shows these results in a more detailed way. So, regarding the research hypothesis, it is possible to observe that the results obtained are: $\beta=0.587, p<0.001$, which indicate that the innovation has positive and significant effects in the adoption of digital marketing in enterprises of Aguascalientes. 
Table 3. Results from the structural equations model

\begin{tabular}{llll}
\hline Hypothesis & Structural relationship & $\begin{array}{l}\text { Standardized } \\
\text { Coefficient }\end{array}$ & Robust Value t \\
\hline $\begin{array}{l}\mathrm{H}_{1}: \text { Higher innovation, the higher adoption of the } \\
\text { digital marketing. }\end{array}$ & Innovation $\rightarrow$ Digital Marketing & $0.587^{* * *}$ & 14.645 \\
\hline $\mathrm{S}-\mathrm{B} \chi^{2}(\mathrm{df}=407)=631.1460 ; \mathrm{p}<0.00000 ; \mathrm{NFI}=0.870 ; \mathrm{NNFI}=0.937 ; \mathrm{CFI}=0.949 ; \mathrm{RMSEA}=0.046$ & & \\
\hline$* * *=\mathrm{p}<0.001$ & & \\
\hline
\end{tabular}

\section{Findings and Conclusions}

The results obtained in this research highlight the importance of innovation inside enterprises in order to adopt digital marketing as one of the ways to carry out the strategic planning of marketing in enterprises of Aguascalientes (Mexico), since there is enough empirical evidence to assume that the enterprises of the state have the necessary innovation regarding the equipment as well as the fact that they have use it as a means for the implementation of digital marketing. Therefore, it is possible to confirm the importance that these two variables are getting inside the behavior of enterprises besides the enormous competitive advantage that they obtain by using or implementing the variables in the activities of their organizations.

Similarly, in the analysis of the theoretical research model (innovation and the adoption of digital marketing in enterprises of Aguascalientes), the statistical results allow us to conclude that, regarding the construct of innovation, it is possible to measure it through the four dimensions and twenty items established as the statistical process shows the existence of reliability of the scale and the validity of the content (construct and discriminant). Regarding the construct of the adoption of digital marketing, it is also considered possible to measure it through its five original dimensions but only with twelve items, which proved the existence of reliability in the scale as well as the validity of content on both the construct and the discriminant.

\subsection{Practical Implications}

From the managerial point of view, the advantages that executives can have, regarding the innovation of products and the adoption of digital marketing, would need to take some immediate actions to keep updating the available equipment in the company such as computers, the internet broad band, tablets, cell phones or any other device that they use to implement some digital marketing strategies because these aspects will help them to solve more direct and faster any question or problem expressed by clients, providers or the general audience. Moreover, there would be a better performance regarding the innovation of processes because an official web site or profile in business social networks it is possible to share a lot more information than the one of a flyer, banner or radio commercial. It can be inferred that, indirectly, it would improve the prestige of the company from the perspective of consumers because companies would stop using invasive methods so the client can obtain all the information needed from the web.

Regarding marketing innovation, it can be said that most enterprises are pioneers in this type of innovation as they never had had to use the Internet to promote their products besides the fact that it is more personalized and direct; it is a lot more dynamic or interactive and the modern consumer needs to be heard. For this reason, digital marketing offers the option of using a two-way communication with the consumer in real time as the enterprise will be available 24-7 to care for the needs and demands of the market. Accordingly, this innovation can achieve a higher and better positioning at a local, national and international level since a correct implementation of digital marketing could imply that the enterprise will be known globally because the use of internet has erased the geographical barriers so a local business can be known in any part of the world. Considering this, and thanks to this new way of advertising, executives can cut down advertising costs in traditional campaigns because they would not invest too much in the use of traditional means completely. They could invest less income with websites or social networks and reach more people. More importantly, they could reach the right people, which is also a benefit for the company.

Finally, for the benefits implied in the organization innovation and the adoption of digital marketing, it can be inferred that the external relations of the company would improve since it would be possible to contact their clients and suppliers with the benefits of the email, web site or profile of the social network. As it was mentioned in previous paragraphs, the openness of the enterprise to provide current and potential clients, suppliers and general public through digital media to give them a recommendation, solve a question or a problem could promote a positive image with the external market and it would also be an easy way for the company to obtain relevant information about the current and potential market for future decision making. 
On the other hand, the results obtained with the present research show positive and significant effects of innovation regarding the adoption of digital marketing in enterprises. Consequently this result represents clear evidence for executives that are still unsure to adopt not only innovation (product, process, marketing and organization) but also for those who feel doubtful about innovating in the administrative processes such as the planning and implementation of marketing in the virtual environment (digital marketing). Additionally, the aspect of adopting of digital marketing as a means to attain some marketing goals can provide guidelines for the growth of the organization as they would not pay attention only to the local market, but it would also give them the possibility of participating into the national and international markets.

\subsection{Limitations}

It is important to mention the limitations observed during the development of this research. One of them was that the size of the sample since only 256 questionnaires was obtained from the 300 that were sent. This represents $85 \%$ of the sample. Also, the interviews engulfed every size of enterprise in the state of Aguascalientes, which belong to the business; industry and services sectors so future investigations need to consider increasing the size of the sample and even analyze both variables in enterprises from other states or countries. Accordingly, another limitation was the gathering of data as there is nowadays mistrust from executives to provide the information requested in the instrument. Many managers concurred that the information requested was highly confidential and private and this complicated the gathering of data.

Finally, one of the most important limitations for this research was to find out that there are enterprises that still have not adopted digital marketing, as part of their marketing strategies or they have preferred to ignore the digital media. This made the gathering of data difficult even when they had all the necessary infrastructure (computers, Internet, smartphones) to implement it. Based on this, it is important to show the results of the present research so executives or people interested in this topic know the relevance of innovation and the adoption of digital marketing, nowadays as well as the implications that both variables have for enterprises. On the other hand, it is important to invite scholars and researchers to delve into the theoretical and empirical study of digital marketing in order to contribute to show the current importance of the adoption and use of e-business because the results obtained could be interesting and a great contribution to the community.

\subsection{Recommendations for Future Research}

Future research should consider investigating digital marketing in a deeper way in other states in Mexico, because no matter that we can live in the same country, it's possible identify the differences in the adoption of digital marketing due the geographic location, for example, the influence of the northern countries in contrast to the states near the southern border, moreover, a larger sample of participants companies in order to obtain a more generalizable result, coupled with this, it's necessary extend the collection time of information. Likewise, being a little more ambitious, we can consider a contrast study between Mexico and other Latin American countries, in which analyze the depth impact of the variables and the competitiveness vision of each country in adoption of digital marketing and innovation.

\section{References}

Abrahamson, E., \& Rosenkopf, L. (1993). Institutional and competitive bandwagons: using mathematical modeling as a tool to explore innovation diffusion. Academy of Management Review, 18(3), 487-517.

Amin, A. (1999). An Institutionalist Perspective on regional economic development. International Journal of Urban \& Regional Research, 23(2), 365-379. https://dx.doi.org/10.1111/1468-2427.00201

Anderson, J., \& Gerbing, D. (1988). Structural equation modeling in practice: a review and recommended two-step approach. Psychological Bulletin, 13, 411-423. https://doi.org/10.1037/0033-2909.103.3.411

Arendt, L. (2007). Barriers to ICT adoption in SMEs: how to bridge digital divide? IADIS International Conference e-Commerce.

Bagozzi, R. P., \& Yi, Y. (1988). On the evaluation of structural equation models. Journal of the Academy of Marketing Science, 16(1), 74-94. http://dx.doi.org/10.1007/BF02723327

Baldridge, V., \& Burnham, R. (1975). Organizational innovation: industrial, organizational, and environmental impact. Administrative Science Quarterly, 20, 165-176. https://doi.org/10.2307/2391692

Bentler, P. (1990). Comparative fit indexes in structural models. Psychological Bulletin, 107(2), 238-246. https://doi.org/10.1037/0033-2909.107.2.238

Bentler, P. (2005). EQS 6 Structural Equations Program Manual. Encino, CA: Multivariate Software. 
Bentler, P., \& Bonnet, D. (1980). Significance tests and goodness of fit in analysis of covariance structures. Psychological Bulletin, 88, 588-606. https://doi.org/10.1037/0033-2909.88.3.588

Braun, P. (2002). Networking tourism SMEs: E-commerce and e-marketing issues in regional Australia. Information Technology \& Tourism, 5, 13-23. https://doi.org/10.3727/109830502108751028

Brodie, R., Winklhofer, H., Coviello, N., \& Johnston, W. (2007). Is e-marketing coming of age? An examination of the penetration of e-marketing and firm performance. Journal of Interactive Marketing, 21(1), 2-21. https://doi.org/10.1002/dir.20071

Brown, T. (2006). Confirmatory Factor Analysis for Applied Research. New York: The Guilford Press.

Byrne, B. (1989). A Primer of LISREL: Basic Applications and Programming for Confirmatory Factor Analysis Analytic Models. New York: Springer. https://doi.org/10.1007/978-1-4613-8885-2

Byrne, B. (2006). Structural equation modeling with EQS, basic concepts, applications and programming (2nd ed.). London: LEA Publishers.

Chaffey, D., \& Ellis-Chadwick, F. (2014). Marketing digital, estrategia, implementación y práctica. México: Pearson.

Chau, P. (1997) Reexamining a model for evaluating information center success using a structural equation modeling approach. Decision Sciences, 28(2), 309-334. https://doi.org/10.1111/j.1540-5915.1997.tb01313.x

Christensen, C. (1997). The innovator's dilemma: when new technologies cause great firms to fail. Boston: Harvard Business School Press.

Ciarniene, R., \& Stankeviciute, G. (2015). Theoretical framework of e-business competitiveness. Procedia Social and Behavioral Sciences, 213, 734-739. https://doi.org/10.1016/j.sbspro.2015.11.528

Cooke, P. (1996). The new wave of regional innovation networks: analysis, characteristics and strategy. Small Business Economics, 8(2), 159-171. https://doi.org/10.1007/BF00394424

Damanpour, F. (1987). The adoption of technological, administrative, and ancillary innovations: impact of organizational factors. Journal of Management, 13, 675-688. https://doi.org/10.1177/014920638701300408

Dlodlo. N., \& Dhurup, M. (2013). Drivers of e-marketing adoption among small and medium enterprises (SMEs) and variations with age of business owners. Mediterranean Journal of Social Sciencies, 4(14), 53-66. https://doi.org/10.5901/mjss.2013.v4n14p53

Drucker, P. (1954). The practice of management. New York: Harper \& Row Publishers.

Drucker, P. (1985). Innovación y emprendimiento. Library Journal, 1, 133-176.

Echeverría, J. (2008). El manual de Oslo y la innovación social. ARBOR Ciencia, Pensamiento y Cultura, 184(732), 609-618.

El-Gohary, H. (2010). E-marketing: a literature review from a small businesses perspective. International Journal of Business and Social Science, 1(1), 214-244.

Evans, D. (1996). The merchants in Venice. Computer Weekly, 9(May), 30-34.

Fornell, C., \& Larcker, D. (1981). Evaluating structural equation models with unobservable variables and measurement error. Journal of Marketing Research, 18(1), 39-50. http://dx.doi.org/10.2307/3151312

Galanakis, K. (2006). Innovation process: make sense using systems thinking. Technovation, 26(11), 1222-1232. https://doi.org/10.1016/j.technovation.2005.07.002

Hair, J. F., Anderson, R. E., Tatham, R. L., \& Black, W. C. (1998). Multivariate data analysis with readings. Upper Saddle River, New Jersey: Prentice-Hall.

Hamidi, A., \& Safabakhsh, S. (2011). The impact of information technology on e-marketing. Procedia Computer Science, 3, 365-368. https://doi.org/10.1016/j.procs.2010.12.061

Hart, C., Doherty, N., \& Ellis-Chadwick, F. (2000). Retailer adoption of the internet: implications for retail marketing. European Journal of Marketing, 34(8), 954-974. https://doi.org/10.1108/03090560010331441

Hull, F., \& Hage, J. (1982). Organizing for innovation: beyond burns and stalker's organic type. Sociology, 16, 564-577. https://doi.org/10.1177/0038038582016004006

Jöreskog, K., \& Sörbom, D. (1986). LISREL VI: analysis of linear structural relationships by Maximum Likehood, instrumental variables and square methods. Scientific Software. 
Kimberly, J., \& Evanisko, M. (1981). Organizational innovation: the influence of individual, organizational, and contextual factors on hospital adoption of technological and administrative innovation. Academy of Management Journal, 24, 689-713. https://doi.org/10.2307/256170

Kotler , P., \& Armstrong, G. (2008). Fundamentos de Marketing. London: Pearson.

Kusiak, A. (2007). Innovation: The living laboratory perspective. Computer-Aided Design \& Applications, 4(16), 863-873. https://doi.org/10.1080/16864360.2007.10738518

Küster, I., Vila, N., \& Aldás, J. (2000). Desarrollo y validación de escalas de medida en Marketing. Universitat de València, 1-73.

Luque, T. (2000). Técnicas de análisis de datos en investigación de mercados. Ed. Pirámide.

Mohr, J., \& Sarin, S: (2009). Drucker's insights on market orientation and innovation: Implications for emerging areas in high-technology marketing. Journal of the Academy of Marketing Science, 37(85), 11-22. https://doi.org/10.1007/s11747-008-0101-5

Nunnally, J. C., \& Bernstein, I. H. (1994). Psychometric theory (3rd ed.). New York: McGraw-Hill.

O'Keefe, R. M., O'Connor, G., \& Kung, H. J. (1998). Early adopters of the web as a retail medium: small company winners and losers. European Journal of Marketing, 32(7/8), 629-643. https://doi.org/10.1108/03090569810224038

OCDE. (2005). Oslo Manual. The Measurement of Scientific and Technological Activities Proposed Guidelines for Collecting and Interpreting Innovation Data. OECD. https://doi.org/10.1787/9789264013100-en

Pinzón C. S. Y. (2009). Impacto de la orientación de mercado en la innovación en empresas de Aguascalientes (Tesis Doctoral). Universidad de San Luis Potosí, México.

Rovira, E., \& Tolstoy, D. (2016). The impact of opportunity connectedness on innovation in SME's foreing-market relationships. Technovation, 57(58), 47-57.

Sawhney, A., Mohan, D., \& Zabin, W. (2001). The Seven Steps to Nirvana. New York: McGraw-Hill.

Schumpeter, J. (1934). The Theory of Economic Development. Boston: Harvard University Press.

Selwyn, N., \& Gorard, S. (2002). The Information Age. Technology, Learning and Exclusion in Wales. Wales: University of Wales Press.

Steinhoff, F., \& Trommosdorff, V. (2013). Innovation marketing. In N. Pfeffermann, T. Minshall, \& L. Mortara (Eds.), Strategy and Communication for Innovation. Berlin: Springer. https://doi.org/10.1007/978-3-642-41479-4_10

Trainor, K., Rapp, A., Beitelspacher, L., \& Schillewaert, N. (2011). Integrating information technology and marketing: An examination of the drivers and outcomes of e-marketing capability. Industrial Marketing Management, 40, 162-174. https://doi.org/10.1016/j.indmarman.2010.05.001

Trivedi, J. (2013). A study on marketing strategies of small and medium-sized enterprises. Research Journal of Management Sciences, 2(8), 20-22.

Van Tassel, S., \& Weitz, B. A. (1997). Interactive home shopping: all the comforts of home. Direct Marketing, $59(10), 40$.

Westland, C. J., \& Au, G. (1998). A comparison of shopping experiences across three competing digital retailing

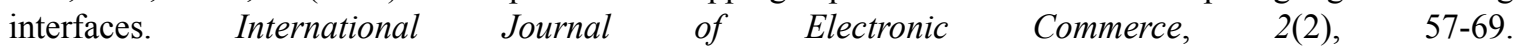
https://doi.org/10.1080/10864415.1997.11518308

Wu, F., Mahajan, V., \& Balasubramanian, S. (2003). An analysis of e-business adoption and its impact on business performance. Journal of the Academy of Marketing Science, 31(4), 425-447. https://doi.org/10.1177/0092070303255379

\section{Copyrights}

Copyright for this article is retained by the author(s), with first publication rights granted to the journal.

This is an open-access article distributed under the terms and conditions of the Creative Commons Attribution license (http://creativecommons.org/licenses/by/4.0/). 